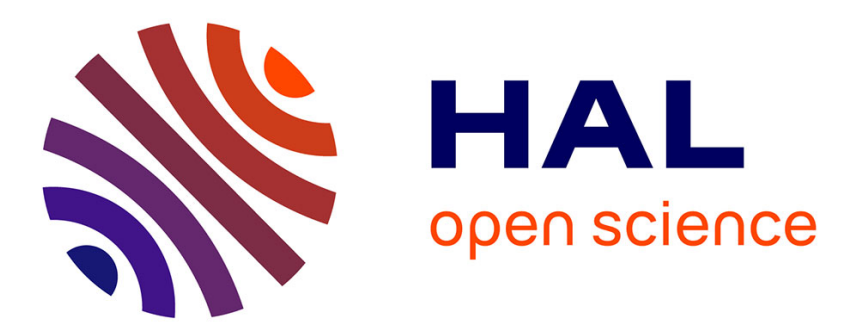

\title{
Construction of an instrument to evaluate the user eXperience of a group of co-creators in the upstream innovation process
}

\author{
Adrien Lecossier, Marc Pallot, Pascal Crubleau, Simon Richir
}

\section{To cite this version:}

Adrien Lecossier, Marc Pallot, Pascal Crubleau, Simon Richir. Construction of an instrument to evaluate the user eXperience of a group of co-creators in the upstream innovation process. International Journal of Services Operations and Informatics, 2019, 10 (1), pp.17-42. hal-02284242

\section{HAL Id: hal-02284242 \\ https://hal.science/hal-02284242}

Submitted on 11 Sep 2019

HAL is a multi-disciplinary open access archive for the deposit and dissemination of scientific research documents, whether they are published or not. The documents may come from teaching and research institutions in France or abroad, or from public or private research centers.
L'archive ouverte pluridisciplinaire HAL, est destinée au dépôt et à la diffusion de documents scientifiques de niveau recherche, publiés ou non, émanant des établissements d'enseignement et de recherche français ou étrangers, des laboratoires publics ou privés. 


\title{
Construction of an instrument to evaluate the user eXperience of a group of co-creators in the upstream innovation process
}

\section{Adrien Lecossier*, Marc Pallot, Pascal Crubleau and Simon Richir}

\author{
Arts et Metiers ParisTech, \\ LAMPA, 2 Bd du Ronceray, \\ Angers, 49000, France \\ Email: adrien.lecossier@ensam.eu \\ Email: marc.pallot@ensam.eu \\ Email: pascal.crubleau@univ-angers.fr \\ Email: simon.richir@ensam.eu \\ ${ }^{*}$ Corresponding author
}

\begin{abstract}
The first part of this paper presents a theoretical model, named UX-FFE, which combines a user eXperience (UX) approach with an upstream innovation process. The main interest of this UX-FFE model is that it allows to evaluate the social aspect of the upstream innovation process, which may be detrimental to the success of radical innovation projects in mature companies. The second part presents the outcomes of the experiment of the model application for the ideation stage of the upstream innovation. The objective of this experiment is to evaluate how much the designed bipolar mixed-method instrument and construct are reliable enough. Finally, the results permit, from the original structure of the UX-FFE model, to construct an instrument $U X i$ dedicated to evaluate the user eXperience of co-creators in ideation stage.
\end{abstract}

Keywords: FFE; fuzzy front end; front end innovation; innovation management; user eXperience; reliability; ideation; assessment; mixed-method.

Reference to this paper should be made as follows: Lecossier, A., Pallot, M., Crubleau, P. and Richir, S. (2019) 'Construction of an instrument to evaluate the user eXperience of a group of co-creators in the upstream innovation process', Int. J. Services Operations and Informatics, Vol. 10, No. 1, pp. $17-42$.

Biographical notes: Adrien Lecossier, MEng, $\mathrm{PhD}$, is a Research Associate at "Laval Arts et Metiers Institute" within the "Presence \& Innovation" research team (LAMPA Lab, EA1427). After had begun his career at the VNIIM Institute in Saint Petersburg, he recently accomplished his work on the radical innovation management proposing a new model which connects humancentred approaches with economical approaches. Considered as the opening of a new territory to explore, this model has made Adrien Lecossier one of the pioneers of radical innovation management in France. Concerned about the industrial applicability of his work, he always keeps a foot in the industrial environment where he officiates as Head of Innovation especially at Esterline or more recently at Primagaz-SHV Energy. 
Marc Pallot, MEng, $\mathrm{PhD}$, is a Senior Research Associate at the Centre for Concurrent Enterprise, University of Nottingham, UK; and at "Laval Arts et Metiers Institute" within the "Presence \& İnnovation" research team (LAMPA Lab, EA1427), France. He is also adjunct faculty member at the Jyvaskyla University of Applied Sciences, Finland. He teaches "User Driven Innovation" and "Innovation Management". Marc was also a member of the AxIS Team at INRIA Sophia Antipolis where he worked on a landscape study at the crossroads of Future Internet, Living Labs and Smart Cities. He has about 20 years industrial experience within Innovation, R\&D, and product marketing \& engineering in various sectors such as Telecom, Avionics, Defense, Engineering and CAD/CAM/PDM. He was formerly Vice-President for Product Marketing \& Engineering at Win Technology; a software house specialised in A.I. based Workflow and Product Data Management.

Pascal Crubleau is a Senior Lecturer, PhD from the University of Angers is renowned for his research work in the field of Innovation. He is an active member of the LAMPA Lab's "Presence \& Innovation" research team (EA1427). His research and teaching fields are based on technological innovation and the product design process. He has put his expertise at the service of the French Ministry of National Education since 2011 as part of the definition of a technological innovation teaching programme at the secondary level. He is the co-author of a software program for learning innovation principles: "Le guide de l'innovation" ([http://www.ingera.com)] www.ingera.com).

Simon Richir, MEng, PhD, is one of the pioneers and the most recognised leaders in French VR research and its practical application. He is a Professor at ENSAM (Arts \& Metiers ParisTech), the renowned French School of Engineering, he is also the Head of "Laval Arts et Metiers Institute" and "Presence \& İnnovation" research team (LAMPA Lab, EA1427). His research and teaching activities concentrate on technological innovation, engineering design process, ideation, innovative projects, and innovative uses of new advanced technologies such as Virtual Reality or Augmented Reality. In addition to these activities, he is also the co-founder and the present scientific chair of one of the world's most prestigious international events in Virtual Reality: The Annual Laval Virtual International Conference.

\section{Introduction}

Managing the disruptive innovation process is a delicate operation for many practitioners. In fact, it requires to navigate and progress inside a stage where uncertainties are high and interactions multidisciplinary (Kim and Wilemon, 2002). Interest in the upstream phase of innovation is steadily increasing. This is understandable since it is in this phase that sustainable value creation projects emerge (Frishammar et al., 2011; Markham, 2013).

The objective is to observe and work on the upstream stage of the innovation process according to the economical, sociological, systemic and operational visions of innovation. This in order to allow a mature industrial company, SOURIAU ESTERLINE, to re-engineer its upstream innovation process through a multidisciplinary concern. Indeed, because the economic, systemic, operational and sociological aspects are confused in a mature industrial enterprise, a multidisciplinary approach is required to 
successfully create and validate breakthrough innovation concepts (Baregheh et al., 2009).

From an economic viewpoint, a mature industrial enterprise seeks to maintain a deterministic and profitable model that it has built over time. For this, it essentially realises incremental innovations that consists in reducing the costs of existing products or improving substantially their performance in order to sustain their market share (Rolstadås et al., 2012). This is why most of the income of a mature industrial enterprise comes from gains made in the mature ecosystem (Porter, 1985). Its economic growth is directly correlated to that of the field of activity in which it operates mainly. A stable and mature company may tend to over-protect its dominant model. This behaviour can lose the sense of objectivity when analysing the changes in its ecosystem. So, in the event of business turbulence or even a questioning of the industrial environment, its comfortable situation can very quickly deteriorate. The most quoted example concerns Kodak, which lost most of its first revenue stream in a few years, refusing to undertake the necessary digital change (Lucas and Goh, 2009). Unfortunately, the same story will happen again and again. These kinds of firm, having a similar Kodak mindset, design new products by systematically improving the dominant model as the basis for innovation. This obsession with the improvement and preservation of the existing dominant model through repeating incremental innovations will undoubtedly lead to their failure in missing breakthrough innovation opportunities.

Rajapathirana and Hui (2017) study presents innovation capability as the most required components for developing effective innovation outcomes within a firm. They define the innovation capability as an ability to understand and identify the future customer needs, expectations and potential customers. Acquire an innovation capability supposes to develop an innovation support organisational culture, to create new ideas and transform them into successful innovations (Rajapathirana and Hui, 2017). Identify the future customer needs, support organisational culture, create new ideas and validated them are activities which characterise operationally the fuzzy front end (FFE) of Innovation (Koen et al., 2001), that we focus on in this paper.

\section{Front end of innovation}

\subsection{Systemic approach: the process view}

The idea of demystifying the operational approach of the upper stage of innovation was born at the end of the 1990s. At that time, it is the downstream process of innovation, more commonly called the Development process which is in the centre of the attention. Obviously, innovation was mainly economically driven through the delivery of higher performances while concurrently reducing costs and time-to-market. To answer these challenges, various methods have emerged between the 1990s and the 2000s. For example, empirical and literature review studies identified input data that is critical to the success of a product's development stage:

1 Customer needs, the concept of the product, the team and the plan of the development project must be well defined.

2 Every product to be developed must be well integrated into the company's development strategy. 
3 Top management must support the development project (Cooper and Kleinschmidt, 1987; Brown and Eisenhardt, 1995).

However, once the demand for radical innovation has arisen, other questions are poppingup: How does a company build critical elements that will ensure success on the market? What process is behind their construction?

As early as 1969, Jewkes et al. (1969) wrote that "the path of innovation is always fuzzy ... there are no shortcuts to succeed, no infallible formulas". Today, we know that this fuzzy path historically called FFE corresponds to a process that is at the first stage of the whole innovation process (Zhang and Doll, 2001). Koen et al. (2001) were the first to structure this fuzzy stage into a clearer process named 'front end of innovation' (FEI) process. The FEI process is a set of five steps working iteratively before the Development stage of the new product development (NPD) process:

1 Opportunity identification: a business organisation identifies the opportunities it would like to pursue. Business and technological opportunities are explicitly considered and will be attributed to new areas of market growth and operational efficiency.

2 Opportunity analysis: opportunities are assessed in order to confirm that it is worth pursuing. Additional information is needed to translate the identification of opportunities into specific business and technology opportunities. This involves making technological and market assessments that are anticipated and often uncertain.

3 Idea generation: it concerns the birth, development and maturation of a concrete idea to the concept form. The generation of ideas is evolutionary. Ideas are built, demolished, combined, remodelled, modified and upgraded.

4 Idea selection: choose among all ideas the one that will, most presumably, achieve the greatest commercial value. There is no single process that guarantees a good selection. The decision methods formalised at this stage are difficult to implement because of the information and limited understanding available. Financial analyses and future income estimates for ideas at this early stage are often wild assumptions. The selection of ideas at this stage is therefore less rigorous than in a development process.

5 Concept validation: this stage consists of providing elements that consolidate the proof of usefulness, profitability and feasibility of the innovative concept. For example, the need should definitely be quantified; users must be qualified...

The activities completed, and decisions taken during the FEI stage represent the starting point of the entire innovation process. In the case of NPD, the performance of the development stage is directly depending on the work achieved during the FEI stage. This effect is called the leverage effect (Verworn et al., 2008). This is why, neglecting the importance of this uncertain FEI stage, can create complications during the development stage, which often leads projects to failure (Tatikonda and Rosenthal, 2000; Zhang and Doll, 2001). In view of the interest it represents, the FEI process has since been supplemented and modified several times by other scholars (Reid and De Brentani, 2004; De Brentani and Reid, 2012). A new step called 'concept selection' had also been added in order to separate the step 'concept and technology development' in two parts. By the 
next we retain the version that orders the FEI in three macro-stages we respectively called: 'strategy', 'ideation' and 'validation' (Lecossier and Pallot, 2017) (Figure 1). This version is a combination of the original FEI process with the innovation pipeline. The 6 FFE steps are then positioned inside the macro-stages.

Figure 1 Reformulated FEI representation used inside our global systemic vision model (see online version for colours)

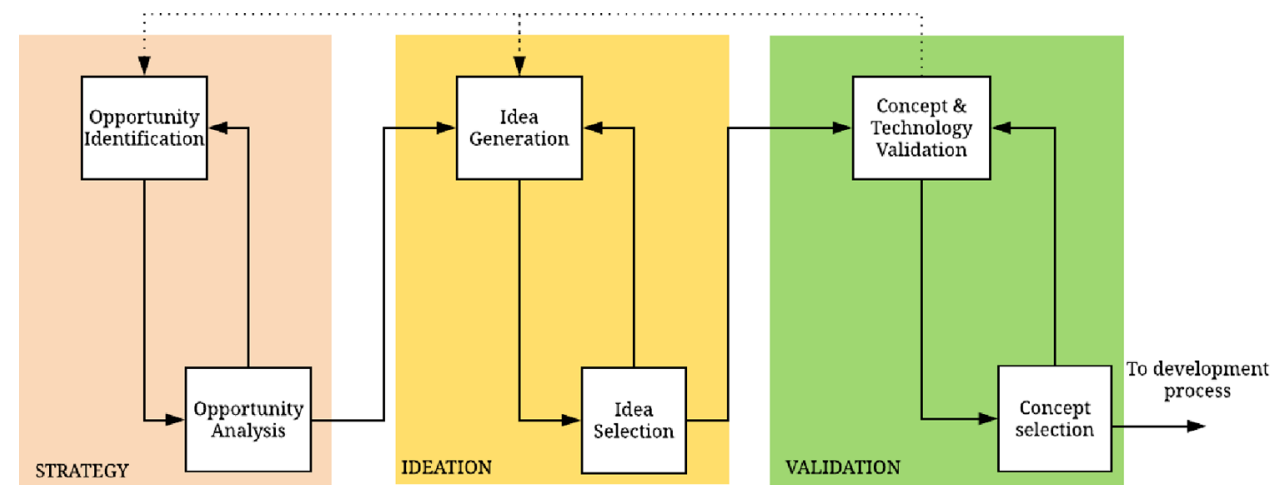

\subsection{Sociological approach: the innovation culture}

According to Koen et al. (2001), the cultural engine is the element having the most important impact on the success of the activities realised during the FEI process. Culture in the FFE fundamentally differs from that in the Development stage of the NPD process (Buckler, 1997). The FFE is experimental, ambiguous, and often chaotic, with a great deal of uncertainty. This is why, the 6 FEI steps can be correctly realised with the presence of a cultural engine which should exist inside the organisation (Dornberger and Suvelza, 2012).

Ahmed define that an organisation in which a cultural engine conducive to radical innovation exists is a structure where for example employees are free, risk-taking is not sanctioned, and hierarchy is reduced to a minimum (Ahmed, 1998). Since then, other researchers have detailed and clarified what are the important factors to facilitate radical innovation. For example, Prather identified five dimensions as the most important for shaping an environment of innovation (Prather, 2000):

1 A compelling challenge that will allow people to become committed emotionally to the project.

2 An environment that allows risk taking. To what degree is it acceptable to not meet expectations when trying something new?

3 Trust and openness that allow people to speak their minds and offer differing opinions.

4 Sufficient time for people to think ideas through before having to act.

5 Availability of funding resources for new ideas.

These results has been confirmed by McLaughlin and al. who analysed 325 pages from 26 interviews and revealed nine key themes that represent aspects of innovation culture 
influencing radical innovation (McLaughlin et al., 2008) (Table 1). Another study confirms these factors at the project level. It shows that there are 5 main managerial lines to follow at the project level to innovate radically (Pihlajamaa, 2017). The first concerns the project goals that should be moderately specified in order to increase individual motivation as the second which suggests breaking radical innovation projects into smaller sub. The third managerial line for radical innovation is putting in place resources for projects. Belonging to a project team with diverse means to approach complex problems may increase the individuals' belief in their ability to reach project goals. The fourth guideline consists to compose a project team with a variety of perspectives and expertise in order to increase individual motivation for radical innovation. Finally, the last managerial good practice at the project level is to reduce bureaucracy.

Table 1 Nine key themes and their archetype for radical innovation, adapted from (McLaughlin et al., 2008)

\begin{tabular}{ll}
\hline Themes & Archetype \\
\hline Freedom/latitude & $\begin{array}{l}\text { Necessary to allow the thinking to go beyond what currently exists. } \\
\text { Exploration and discovery are part of the way things are done. } \\
\text { Attitude to risk }\end{array}$ \\
Taking risks is encouraged. Uncertainty is a part of the environment \\
and discovery is accepted as being linked to taking risk.
\end{tabular}

The upstream process of innovation has been studied from a systemic point of view (FEI process) and from a sociological point of view (managerial and cultural behaviour for radical innovation). To support these results, tools and operational methods have been developed. 


\subsection{Operational point of view: FEI methods and tools}

Indeed, because recent studies confirm that the FEI process is a vital process for the success of new products especially in cases of radical innovation (Markham, 2013), more and more companies are tooling and structuring their FEI process with specific methodologies in order to make it more efficient (Nicholas, 2014).

Many methods have been implemented in recent years to equip the FEI process and largely innovation and NPD processes. Our bibliographic research made on Scopus confirms that there are many methods for each of the FEI steps (Table 2). The following query "(step of the FEI process AND method AND innovation)" yielded a large number of results for all FEI steps. This abundance of tools had already been critiqued by explaining that tools destined to the same purpose do not produce the same results (Benders and Vermeulen, 2002). Bessant's research work has made possible to better organise and use the methodological offer during the FEI process (Bessant and Tidd, 2011). These studies allow to develop a website called "innovation-portal.info" that proposes a toolkit to help practitioners to apply the FEI tools (Bessant, 2018). The tools offered on the website and largely in the literature are interesting and easy to use. However, there is no guarantee that their uses do not go against the managerial principles that favour radical innovation. This is why, we consider that the FEI process and its tools are entering in a paradoxical situation that is described in the next section.

Table 2 Number of results to the query (Step of the FEI process AND method AND innovation) on Scopus

\begin{tabular}{|c|c|c|c|c|c|}
\hline $\begin{array}{l}\text { Semantic } \\
\text { research }\end{array}$ & $\begin{array}{c}\text { (TITLE-ABS- } \\
\text { KEY(opportunity } \\
\text { identification AND } \\
\text { method }) \text { AND } \\
\text { (Innovation) }\end{array}$ & $\begin{array}{c}\text { (TITLE-ABS- } \\
\text { KEY(opportunity } \\
\text { analysis AND } \\
\text { method }) \text { AND } \\
\text { (Innovation) }\end{array}$ & $\begin{array}{c}\text { (TITLE-ABS- } \\
\text { KEY(idea } \\
\text { generation AND } \\
\text { method)) AND } \\
\text { (Innovation) }\end{array}$ & $\begin{array}{l}\text { (TITLE-ABS- } \\
\text { KEY(idea } \\
\text { selection AND } \\
\text { method) }) \text { AND } \\
\text { (Innovation) }\end{array}$ & $\begin{array}{c}\text { (TITLE-ABS- } \\
\text { KEY(concept } \\
\text { validation AND } \\
\text { method) } \text { AND } \\
\text { (Innovation) }\end{array}$ \\
\hline $\begin{array}{l}\text { Number of } \\
\text { results }\end{array}$ & 543 & 4104 & 743 & 380 & 540 \\
\hline
\end{tabular}

\section{Limits of the front end of innovation process and associated tools: the innovation structuration paradox}

As we saw, the literature identifies a multitude of methods to make each step of the FEI process operational. But methodological abundance is a risk for two reasons:

1 Difficulties in the choice of the method: whether in the literature or in the commercial offers, there are few approaches that specify at which stage of the process a method can be used. In addition, it is common to see that some techniques intended to produce an incremental result are used in a disruptive innovation project and vice versa.

2 Excessive structuring of a phase that must remain organic: beyond their positioning and efficiency levels, methods for the upstream phase of innovation are increasingly structuring. A methodological accumulation can be the source of a counter-inertia impacting the cultural engine essential to the good functioning of the FEI process. 
We highlight a paradox whose risk of occurrence is not low in environments constrained by standards and total quality management such as the aeronautical field. This paradox is a way to avoid when one knows that radical innovation appears in a flexible environment.

\section{Model proposals}

To get around the paradox, we have chosen to extend the FEI process with a user eXperience (UX) approach in order to support the sociological viewpoint inside a systemic structuration.

It is today still difficult to find a consensus, between researchers and practitioners, on what UX is (Scapin et al., 2012). For example, Law et al. (2009) claim that: "UX is dynamic, context dependent, and subjective". ISO FDIS 9241-210 (2009) defines UX as "all aspects of the user's experience when interacting with the product, service, environment or facility". The "user is at the centre of design" becomes the watchword. Therefore, UX has been in the last years an approach used in numerous disciplines (e.g., human computer interaction (HCI), ergonomics, information architecture, branding, etc.) to improve user-centric products or services. According to Pallot and Pawar (2012), UX is a multi-dimensional and multi-faceted concept reflecting many different types of experience, including social and empathical experiences, that users can live through when using a product/service. They also suggested that each type of experience is then decomposed into elements and properties for the evaluation of its perceived quality.

\subsection{Model principle}

The introducing of UX in our field of research consists to consider the FEI process and its methodologies as systems. This means that we are interested in the feelings of people who use the methodologies and methods of the FEI process. Indeed, while a method is operationally structuring to be effective, its use must in no case give rise to a sense of bureaucracy, under penalty of entering a paradoxical situation.

Finally, the principle of our model proposal consists to ensure that a person who follows the FEI process and apply its methodologies can experience a good quality of experience, avoiding the paradox effect of the process structuration and increasing the performance of breakthrough creation and validation. It allows taking concurrently into account the social and economic aspects necessary for the breakthrough and radical innovation creations.

Figure 2 presents a scheme of the UX-FFE model principle. The analogy achieved with the field of electricity aims to facilitate the understanding of the principle of the model. It supposes to consider that each phase of the process has a capacity $C x$ allowing to identify, to make emerge and to validate breakthrough and radical ideas. This ability can be improved through the use of tools and methods. Each phase of the process produces a result noted $I x$ corresponding to the operational radical innovation project performance. Finally, as we saw, each phase of the process is subject to the cultural engine which by analogy can be considered as a 'social voltage' noted $U X X$.

Therefore, identify and validate UX experience types which allow to evaluate $U X x$ is truly important because of their direct impact on the FEI process performance. It is this research topic that we will treat in this paper. Indeed, despite the amount of research 
works there is no UX approach dedicated to the interaction of a person with a process and methodology. In fact, most of UX approaches used inside the innovation processes are dedicated to optimise the quality of experience with the product/service that a user is designing. However, we retained the Holistic Model of User Experience (HMUE) as base because its components are enough general and consequently adaptable to characterise system interactions (Pallot and Pawar, 2012) (Figure 3). The HMUE model is composed of four dimensions: human, social, societal and business. Each dimension is evaluated by different experience types. For example, the social dimension is evaluated by two experiences: interpersonal and emphatical. And these experiences are constituted of element: Social ties, Interaction and Group dynamics for the Interpersonal experience; caring for the emphatical experience. Finally, elements are evaluated by the properties as for example 'sense of community' and 'sense of indulgence' for the caring element.

Figure 2 Representation of the UX-FFE model principle using an analogy with the electrical field (see online version for colours)

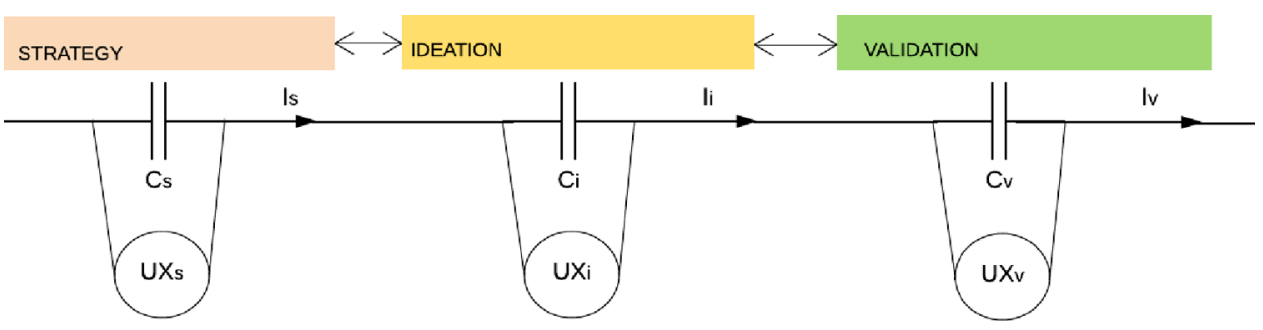

Figure 3 A holistic user eXperience model (see online version for colours)

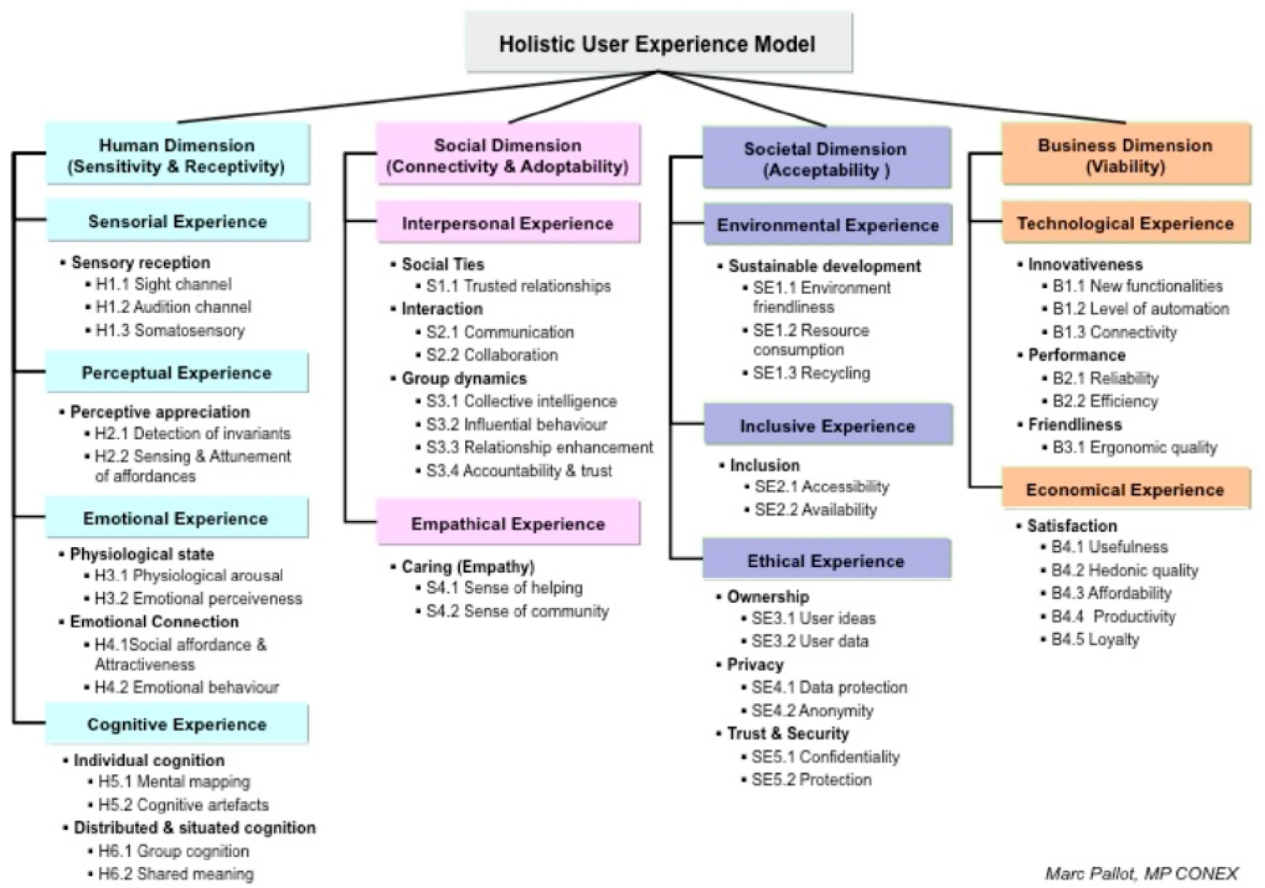


Therefore, the HMUE components we want to link with the FEI process should rationally be linked to the cultural engine definition. In order to establish link, we applied the instantiation method as proposed by Krawczyk et al. (2017).

\subsection{Instantiated UX model}

The instantiation method consists of checking the correspondence between value elements, to be delivered to the users by the investigated solution (FEI process, methodologies), and UX elements appearing in the holistic UX model (Figure 3). In other words, a subset of relevant UX components and properties from the holistic model is turned into an implemented model according to the characteristics of the proposed solution to be adopted by users. For example, in order to delivering the value of the positive or negative impact caused by a methodology which makes a hierarchical distinction between users it is anticipated that "group dynamics" element is relevant. The reasoning is the same for each of the engine element. One should answer the next questions:

1 "What is the HMUE dimension which characterises the studied engine property?"

2 "In the selected dimension, what is the type of experience corresponding to the engine property description?"

3 "In the selected type of experience, what is (are) the element(s) of the HMUE allowing to evaluate the engine property?"

4 "In the selected HMUE element, what is (are) the property(ies) of the HMUE allowing to evaluate the engine property?"

Table 3 presents some matches of the HMUE components with some of the cultural engine elements after the instantiation method has been realised.

The overall UX-FFE construct contains three dimensions, six types of experience, nine elements and 20 properties (Appendix A).

Table 3 Example of the instantiation method application: links between elements of the cultural engine and the Holistic model of user eXperience

\begin{tabular}{|c|c|c|c|c|}
\hline \multicolumn{2}{|c|}{$\begin{array}{c}\text { Some of cultural engine components (Ahmed, } \\
\text { 1998; McLaughlin et al., 2008) }\end{array}$} & \multicolumn{3}{|c|}{$\begin{array}{c}\text { Some of Holistic model of user eXperience components } \\
(\text { Pallot and Pawar, 2012) }\end{array}$} \\
\hline Engine elements & Element properties & Dimension & Type of experience & Element \\
\hline $\begin{array}{l}\text { Organic } \\
\text { structures }\end{array}$ & $\begin{array}{l}\text { face to face } \\
\text { communication; } \\
\text { little red tape }\end{array}$ & Social & $\begin{array}{l}\text { Interpersonal } \\
\text { experience }\end{array}$ & $\begin{array}{ll}\text { - } & \text { Social ties } \\
\text { - } & \text { Interaction } \\
\text { - } & \text { Group dynamics }\end{array}$ \\
\hline $\begin{array}{l}\text { Freedom/ } \\
\text { attitude to risk }\end{array}$ & $\begin{array}{l}\text { allow discussion of } \\
\text { dumb ideas }\end{array}$ & & & \\
\hline
\end{tabular}

\subsection{Survey instrument}

To ensure that UX components we selected to characterise the UX-FFE model are reliable, we should statically validate them for the three 'social voltages' of the UX-FFE model, noted $U X s, U X i$ and $U X v$ (Figure 2). 
From the metrological point of view, the UX measurement is today still immature and not reliable (Lecossier et al., 2017). Indeed, according to the International Vocabulary of Metrology (i.e., VIM 3), a measurement process should generate "one or more quantity values that can reasonably be attributed to a quantity". Moreover, "the results of the process, by which quantity values have been obtained, are characterised by the metrological compatibility, metrological comparability and, if necessary, metrological traceability".

To face this problematic situation, we decide to use an evaluation method which combines quantitative and qualitative evaluations (Cresswell et al., 2003). According to Krawczyk et al. (2017) the using of a mixed method (MM) allows for more confident interpretation of the results as well as early detection of potential problems with the reliability and validity of the UX survey instrument and/or collected data. Therefore, as in their study dedicated to a mobile app, we decide to base our research approach on MM concurrent strategies with the qualitative part embedded into the quantitative one.

The instrument is a bipolar survey that embeds an open-ended question for each rating question in order to capture respondents' justifications behind their ratings. Each question that contains the survey should allow evaluating the anticipated properties that constitute the UX-FEE model (Appendix A).

\subsection{Experiment}

Both the tool and the survey instrument were pilot-tested with a minimum of 67 participants; all students in a master 1 level of a French engineering school specialised in the industrial sciences.

The participants were invited to participate in a day of creativity called 'creative day' inside an industrial company. Students formed 12 groups of 10 students; each accompanied by a coach. Their goal was to conceive and model ideas answering to the company challenge. We assume that the activities realised during the day correspond to activities currently realised during the 'generation idea' step of the FEI process. Then, data collected correspond to the $U X i$ evaluation.

Three days after the event, the UX survey instrument was sent by e-mail to the 120 participants of the 'creative day' and 112 of them answered between 4 and 10 days after the reception. The response rate is equal to $93.3 \%$.

\subsection{Data collection}

Respondents $(n=112)$ filled out the above described UX survey instrument including: (1) Quantitative measure through the use of a bipolar rating based on a semantic scale. For example: 0: Useless, 1: Mostly useless, 2: Almost useful, 3: Mostly useful, 4: Useful; and (2) Qualitative open-ended question for giving a justification/reason for each rating. Qualitative data were transformed into negative or positive comments and in some cases into both. Negative comments were turned into value ' 0 ' while positive comments were turned into value ' 1 '. When negative and positive comments cancelled each other out for the same rating they were turned into value ' 0.5 '. 
Table 4 Results in term of descriptive statistics (part1)

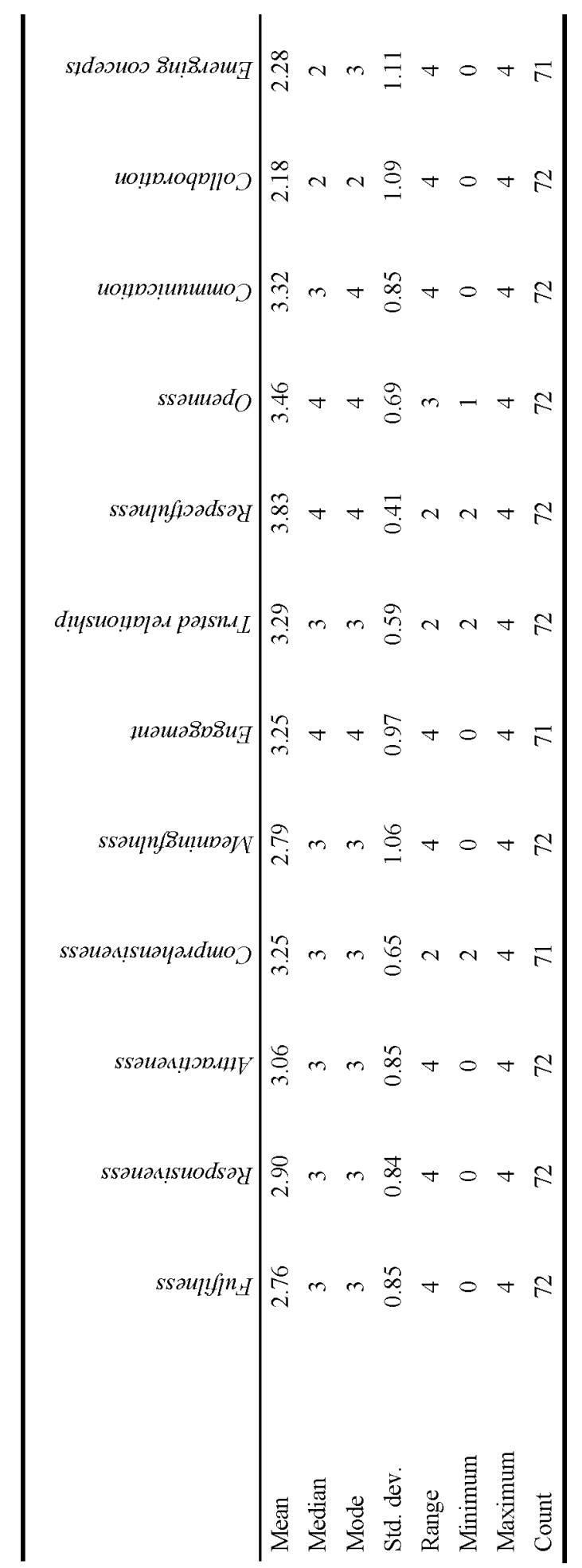


Table 5 Results in term of descriptive statistics (part 2)

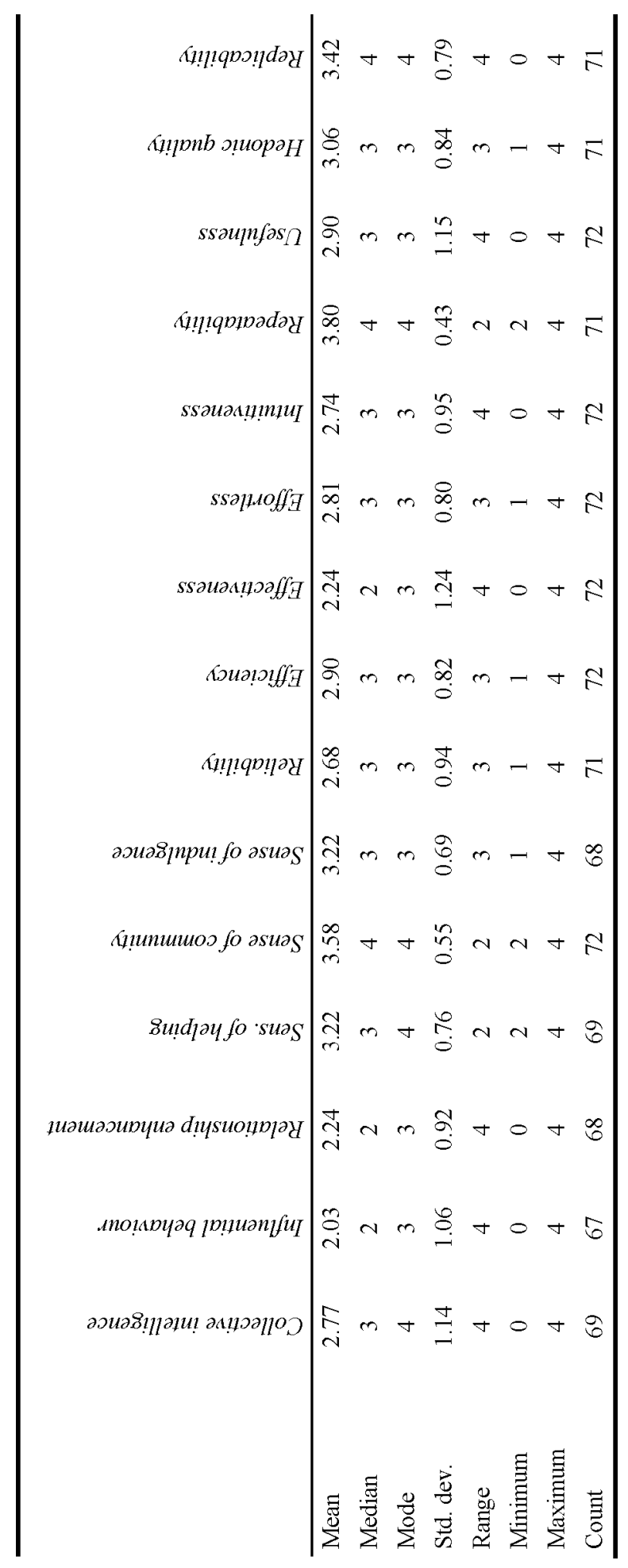




\subsection{Sampling}

Seventy-two of the 112 responses were selected. Some answers have missing data for questions with a bipolar survey. An item answer with missing data is not included in the descriptive statistics of the item (Tables 4 and 5). The participation rate for open questions is $75 \%$.

\section{Analysis and finding}

\subsection{Quantitative and qualitative results of the UX of the idea generation activity: $\boldsymbol{U X \boldsymbol { i }}$}

As explained in the above Section 4.3 dedicated to the research approach about mixed methods concurrent strategies, quantitative and qualitative data are compared using the concurrent triangulation strategy approach. In Figure 4, the means of negative and positive comments given for each rating appears in the form of a bar graph while the means of the bipolar rating for each UX property appears as a dotted curve. The width of the error bars represents the standard deviation of the data for each property.

Figure 4 Results of the UX of the idea generation activity for all 27 properties (see online version for colours)

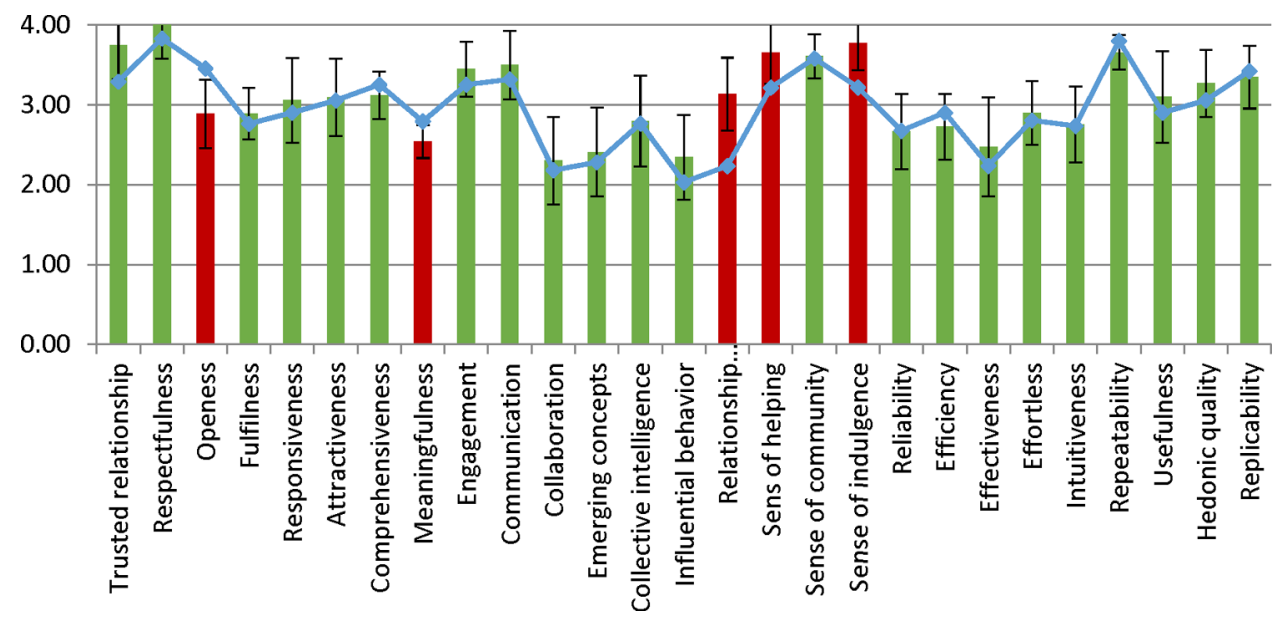

Along the $X$-axis, there are the 27 properties corresponding to the 27 bipolar questions. Along the $Y$-axis, there is the rating scale from 0 to 4 . The first level from 0 to 1 is considered 'unsatisfactory'; the second level from 1 to 2 is named 'mostly unsatisfactory'; the third level from 2 to 3 is considered 'mostly satisfactory'; finally, the fourth level is labelled as 'satisfactory'.

The same axis is also used for representing the negative comments (value 0) at $Y: 0$ and positive comments (value 1) at $Y: 4$ as well as cancelled out/simultaneous negative and positive comments (value 0.5) at $Y: 2$. The bars coloured in red (openness, meaningfulness, relationship enhancement, sense of helping, sense of indulgence) represent the mean between negative and positive comments being below or above the level of the ones resulting from the ratings (dotted curve). The bars coloured in green 
represent the mean between negative and positive comments rising at about the same level of the rating mean. It means that for $22 \mathrm{UX}$ properties, the level of rating is confirmed by the mean of collected qualitative comments (Figure 4).

The difference between the evaluation resulting from the rating and the qualitative evaluation is higher than the standard deviation of the data for five properties (openness, meaningfulness, relationship enhancement, sense of helping, sense of indulgence). However, no result of the qualitative evaluation opposes a result of the evaluation resulting from the rating. This means that the significant difference between the two assessments does not call into question the nature of results (unsatisfactory vs. satisfactory).

\subsection{Descriptive statistics}

All items were evaluated on a scale from 0 to 4 . We can see that all scores are on average higher that the middle level (value: 2) (Tables 4 and 5). In addition, medians and modes rarely inferior to 3 show that the experience was perceived as positive for almost all properties. The lowest coefficient of variation is $11 \%$ (Respectfulness) and the highest $55 \%$ (Effectiveness). In average, coefficient of variation is equal to $31 \%$, which shows moderate diversification of users' opinions. Respectfulness property has the highest mean and lowest standard deviation (the lowest diversification), which may limit its performance as a scale (evaluation).

Observing means for different groups (created by type of comment) we can clearly see coherence between qualitative and quantitative feedback (Table 6). The N/A indications mean that there was no 'negative' comment for the respectfulness, sense of indulgence and repeatability elements. For all items except 'sense of indulgence', group mean values are the lowest for 'negative' comment, highest for 'positive' comment and in between those two for 'both' comments. The only exception is Sense of indulgence, where the mean value for 'both' is slightly higher than for 'positive'.

The use of descriptive statistics to analyse the data makes possible to verify that the answers are coherent. On the other hand, these results do not allow saying whether the bipolar mixed-method instrument and construct are reliable enough to correctly evaluate $U X i$. The next part of the paper presents the reliability analysis of the bipolar mixed-method instrument and construct.

\subsection{Reliability analysis}

\subsubsection{UX evaluation reliability at the elements level}

Cronbach's alphas are at an acceptable level (higher or close to 0.7 (Nunnally, 1967; O'Leary-Kelly and Vokurka, 1998)) for 4 out of 9 elements of the UX-FFE construct, namely: emotional connection, Social ties, Interaction and Satisfaction. Social ties and Interaction variable have respectively Cronbach's alpha equal to 0.65 and 0.66 . It is a bit low but we can say it is satisfactory considering exploratory studies (Kline, 2000). For five elements, namely: group cognition, group dynamics, caring, performance and friendliness, alphas are respectively not satisfactory. We cannot confirm strong scale

reliability for all elements (Table 7). Pearson correlation coefficients show that emotional connection, social ties, interaction and satisfaction elements have their properties correlated at a very significant level $(0.01)$ or a significant level $(0.05)$. 


\section{Table 6}

$A$ Group means

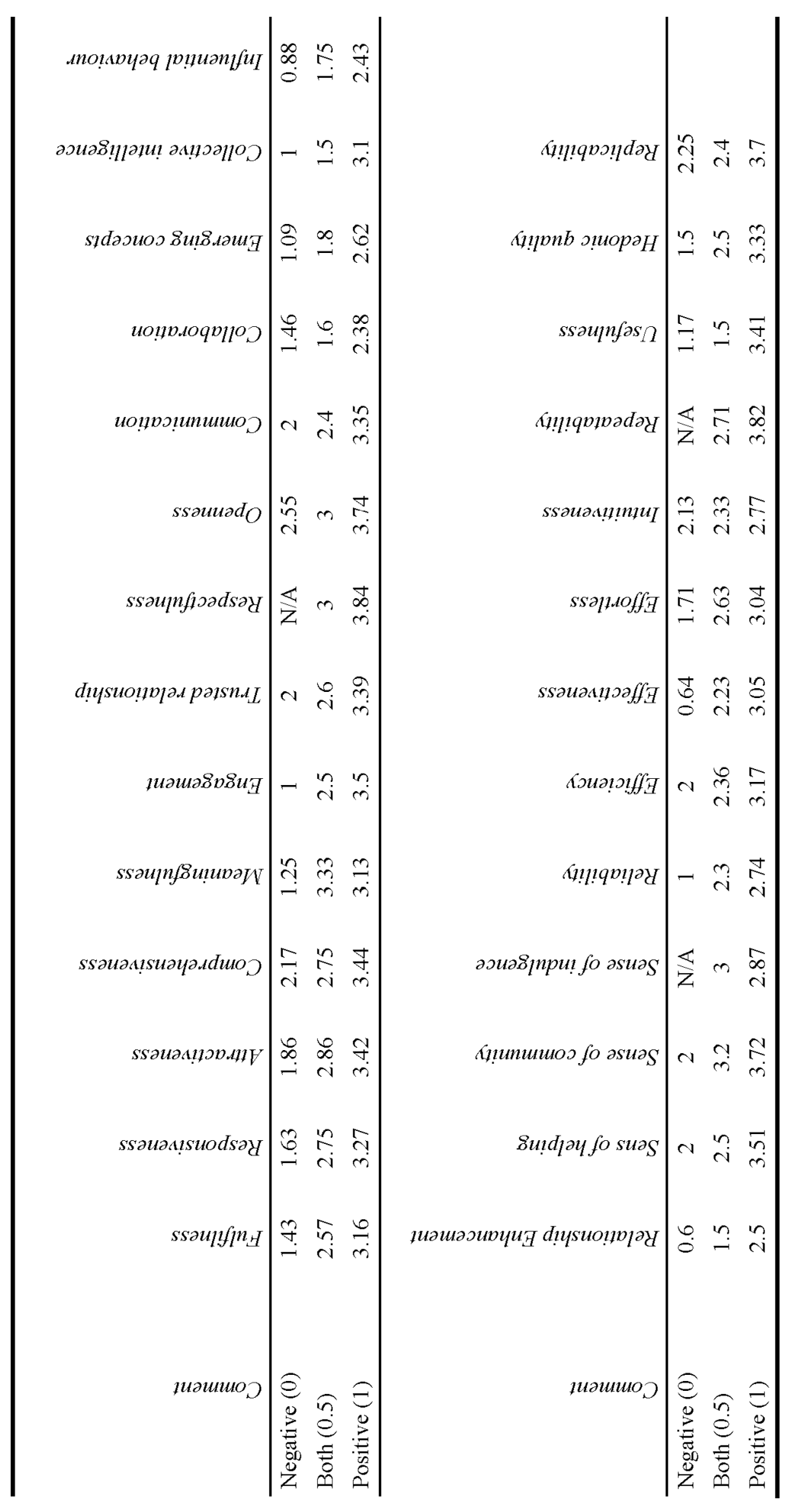


Table 7 Lower level experience construct's reliability measured by Cronbach's alpha and Pearson correlation levels

\begin{tabular}{|c|c|c|c|c|c|}
\hline Element & $\begin{array}{c}\text { Cronbach's } \\
\text { alpha }\end{array}$ & $\begin{array}{l}\text { Average } \\
\text { Pearson } \\
\text { correlation } \\
\text { between } \\
\text { properties }\end{array}$ & $\begin{array}{c}\text { Correlation } \\
\text { significant at } \\
\text { the 0.01 level } \\
\text { (bilateral) }\end{array}$ & $\begin{array}{c}\text { Correlation } \\
\text { significant at } \\
\text { the 0.05 level } \\
\text { (bilateral) }\end{array}$ & $\begin{array}{c}\text { No } \\
\text { significant }\end{array}$ \\
\hline Emotional connection $* *$ & 0.77 & 0.53 & $100 \%$ & - & - \\
\hline Group cognition & 0.21 & 0.076 & - & - & $100 \%$ \\
\hline Social ties* & 0.65 & 0.384 & $66 \%$ & $33 \%$ & - \\
\hline Interaction* & 0.66 & 0.390 & $66 \%$ & $33 \%$ & - \\
\hline Group dynamics & 0.38 & 0.179 & - & $33 \%$ & $66 \%$ \\
\hline Caring & 0.32 & 0.119 & $33 \%$ & - & $66 \%$ \\
\hline Performance & -0.05 & 0.003 & - & - & $100 \%$ \\
\hline Friendliness & 0.52 & 0.243 & $33 \%$ & - & $66 \%$ \\
\hline Satisfaction** & 0.76 & 0.525 & $100 \%$ & - & - \\
\hline
\end{tabular}

*Moderately evaluated; **well evaluated.

Observing correlation coefficients within element types, we can assess how well particular items perform in measuring corresponding elements (Appendix B) and better understand the percentage indicated in Table 7. Smaller rectangles show lower level elements while larger rectangles correspond to the dimensions.

- Two elements can be reliably evaluated:

- Emotional connection: well evaluated with very significant properties correlations (Table 7, Appendix B):

- Satisfaction: high scale reliability.

- Two elements can be moderately evaluated:

- Social ties: Moderately well evaluated with a very significant correlation between 'respectfulness' and 'openness' properties.

- Interaction: Moderately well evaluated with a very significant correlation between its two properties 'collaboration' and 'emerging concept'.

- Four elements are poorly assessed:

- Group cognition: no reliable. No property of the element is significantly correlated with another. The property called 'meaningfulness' seems to be correlated with other properties of the human dimension.

- Group dynamics: no reliable even if two of its properties are significantly correlated (Table 7).

- Caring: no reliable.

- Performance: the worse evaluation reliability level: no reliable.

- Friendliness: low scale reliability, even if the two properties 'intuitiveness' and 'effortless' are significantly correlated. 
Table 8 Element level scale reliability - diagonal and Heterotrait-Monomethod triangle (see online version for colours)

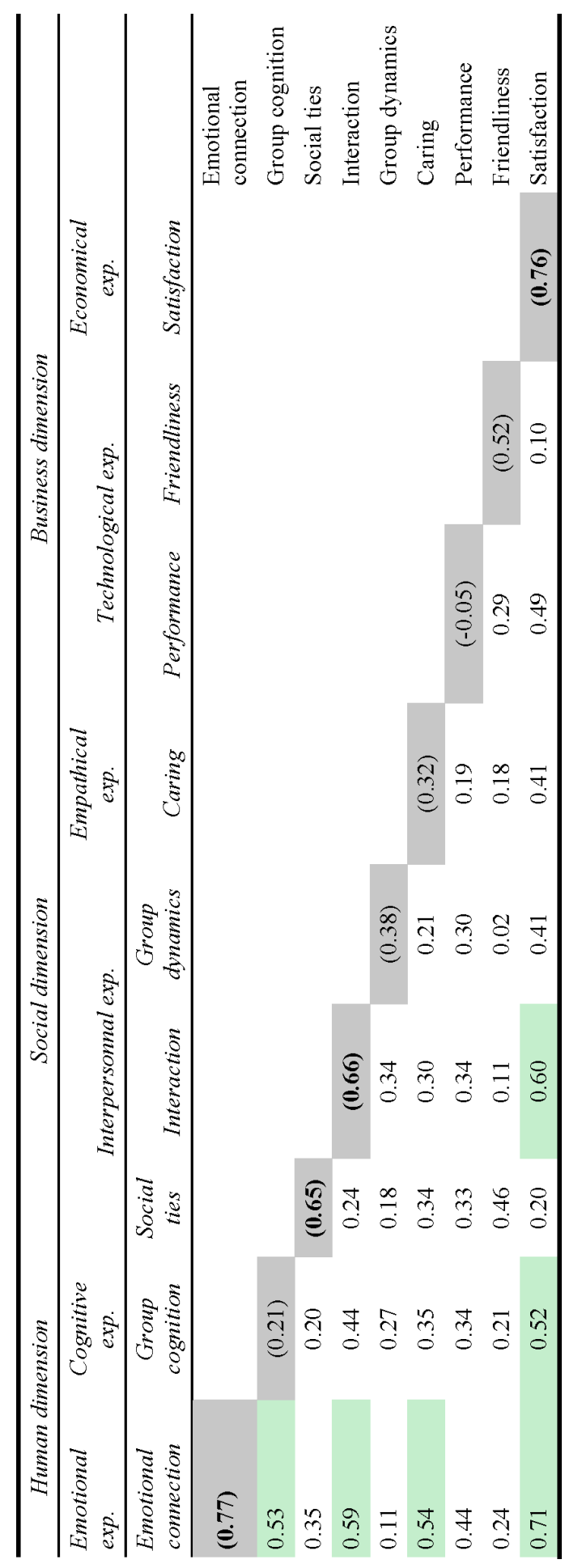


These results allow to understand that the UX evaluation of the ideation generation stage, noted UXi (Figure 2), will be not realised using the full construct of the UX-FFE model (Appendix A). Indeed, only 2 elements are considered as moderately evaluated (social ties and interaction) and 2 elements as well evaluated (emotional connection, satisfaction).

\subsubsection{UX evaluation reliability at the experience level}

In order to validate the ability to use these four elements to assess the $U X i$, the experience evaluations reliability are also analysed by usage of the Diagonal and Heterotrait-Monomethod Triangle (Campbell and Fiske, 1959) (Table 8). Cronbach's alphas and Pearson correlation coefficients for elements are presented in Table 8. Scales for multi-properties elements were calculated as the propriety's average.

Table 8 shows that some elements are significantly correlated with each other. For example, the element 'emotion connection' is significantly correlated with the elements 'group cognition', 'interaction', 'caring' and 'satisfaction'. Correlation coefficient down from the diagonal element and left from the diagonal element should be lower than the diagonal element - it means that questions measure proper construct (this construct not another). In our situation, we can consider that it is the case for the 4 reliable elements (Emotional connection, Social ties, Interaction and Satisfaction). Then, the survey instrument properly evaluates these elements as they are organised inside the UX-FFE construct (Appendix A).

To validate the reliability of the evaluation of an experience type, it is necessary that the elements which compose it are correlated significantly and are themselves evaluated reliably.

- - Two experiences can be reliably evaluated:

- Emotional experience: well evaluated because it is composed of only one element (emotional connection):

- Economical experience: well evaluated because it is composed of only one element (satisfaction).

- - Four experiences cannot be reliably evaluated:

- Cognitive experience: poorly evaluated because it is composed of only one element not reliably assessed (Group cognition).

- Interpersonal experience: not well represents the $U X i$ construct (very low correlation level between its elements). For example, the element 'interaction' is more correlated with 'emotional connection' and 'satisfaction' elements than with 'social ties' element.

- Empathical experience: poorly evaluated because it is composed of only one element not reliably assessed (caring).

- Technological experience: poorly evaluated because its elements are not reliably assessed.

Finally, Table 8 shows that the $U X i$ construct does not follow in full the UX-FFE construct (Appendix A). However, the reliability analysis allows validating that it can be 
composed of four elements: emotional connection, social ties, interaction and satisfaction.

\subsubsection{Finding: UXi evaluation model}

We saw that the full UX-FFE construct is not reliable to evaluate the $U X i$. It needs to be simplified. According to the reliability analysis, the $U X i$ evaluation model is characterised by four elements: emotional connection, social ties, interaction and satisfaction. Two of them represent two types of experience: the emotional experience for the emotional connection element; the economical experience for the satisfaction element.

According to their correlation level (0.24), we can consider that social ties and interaction elements do not compose the same experience type.

Figure 5 represents the raw $U X i$ construct which is based on the results of the reliability analysis. Following the UX-FFE construct logic, we can say that the $U X i$ construct is composed of two experiences types, four elements and 12 properties.

Figure 5 UXi evaluation model

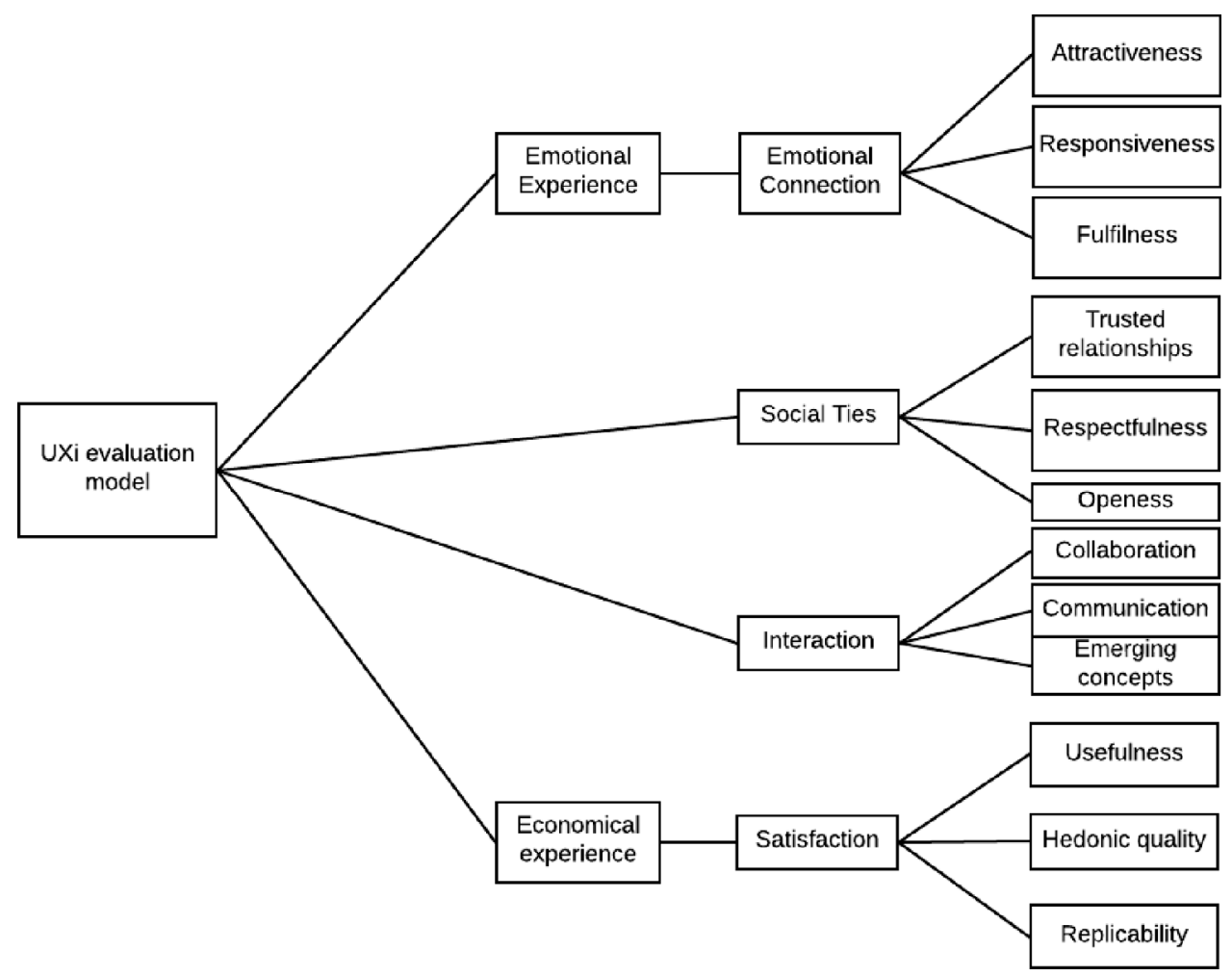

\subsubsection{Reorganised UXi evaluation model}

To respect a similar organisation than the UX-FFE construct based on dimensions, experiences, elements and properties, we decide to reorganise the $U X i$ construct following the reliability and correlation results. 
Figure 6 presents the reorganised $U X i$ construct. It shows that Interaction and Satisfaction elements have been regrouped under a socioeconomical experience. We made this choice because we wanted to conserve a structure based on the three dimensions (human, social, business). The emotional experience represents the human dimension; the interpersonnal experience the Social dimension; and the socioeconomical experience the business dimension.

Figure 6 Optimised UXi evaluation model

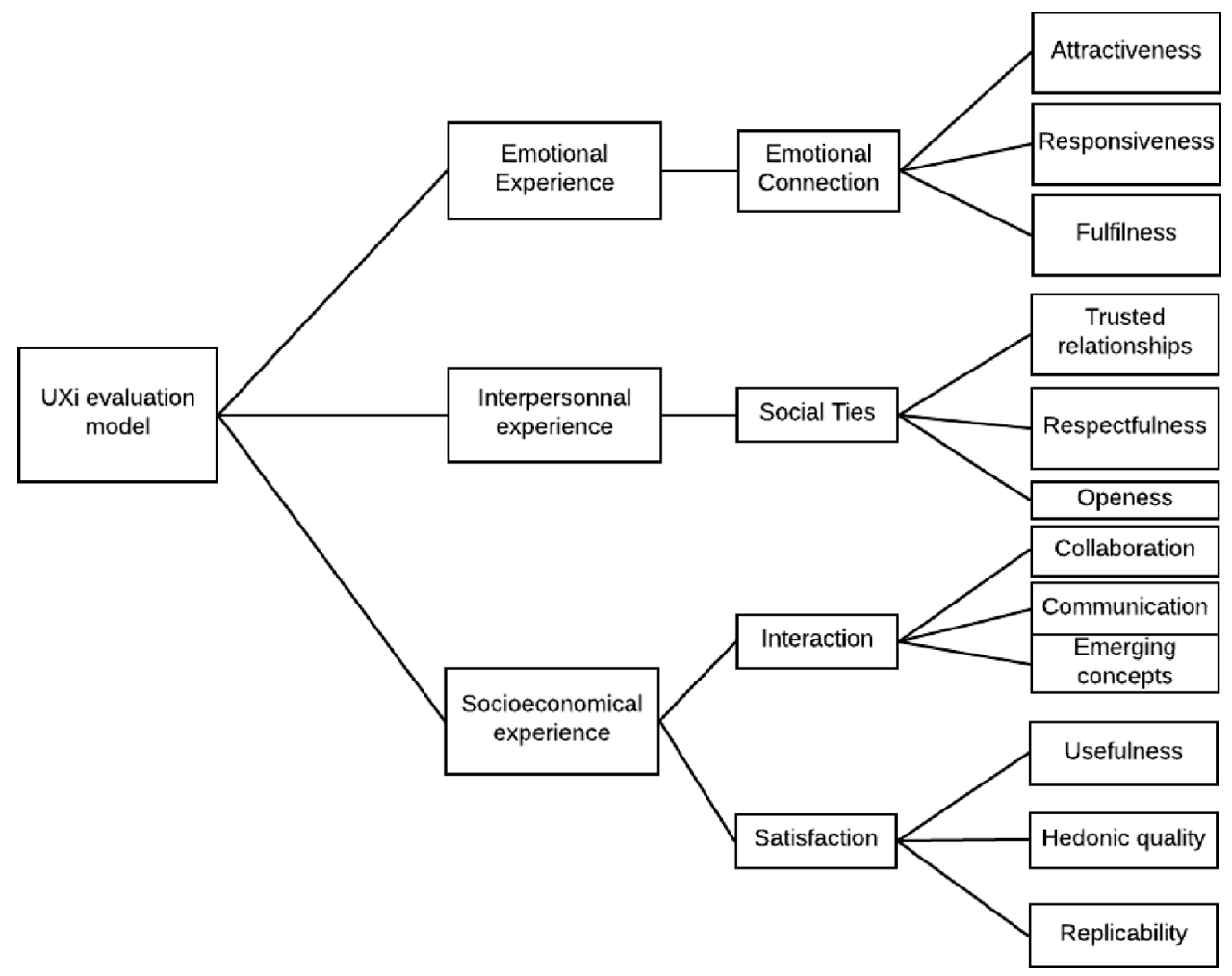

The reliability of the reorganised $U X i$ evaluation model has been analysed by usage of the diagonal and Heterotrait-Monomethod triangle (Table 9). It shows that the socioeconomical experience can reliably be evaluated as the other experience types.

Table 9 Experience level scale reliability of the optimised UXi construct - diagonal and Heterotrait-Monomethod triangle (see online version for colours)

\begin{tabular}{lccl}
\hline Emotional exp. & Interpersonnal exp. & Socioeconomical exp. & \\
\hline $\mathbf{( 0 . 7 7 2 )}$ & & & Emotional exp. \\
0.350 & $\mathbf{( 0 . 6 5 )}$ & & Interpersonnal exp. \\
0.728 & 0.242 & $\mathbf{( 0 . 7 4 )}$ & Socioeconomical exp. \\
\hline
\end{tabular}




\section{Limitation, conclusion and future work}

We saw that the upstream process of innovation has over the years been structured in a systemic way. The FEI process is today the most representative systemic model of the steps to follow to make emerge and validate radical innovative projects.

There are many tools and methods that make each of the six steps of the FEI process operational. However, most tools do not distinguish whether they should be used for making emerge incremental, or radical innovation. Yet this nuance is important for practitioners who wish to lead at best different types of innovative projects with different levels of intensity. That in order to respond to different economical stakes.

Moreover, and it is the topic we treated in this paper, the quantity of tools available leads practitioners to structure the FEI process systematically. At the end, these practices risk to create among others a feel of bureaucracy inside the FEI process. We present in this paper that excessive structuring is a path to avoid in the upstream innovation process. Indeed, it is contrary to the cultural engine essential for the emergence and validation of radically new ideas: it is the paradox of structuring innovation.

To avoid it, we propose a model called UX-FFE that allows structuring the FEI process by ensuring that it is not at the origin of a harmful effect that could impact the inertia of the cultural engine.

Combining the FEI process with an UX approach, our model proposal considers methodologies as systems with which process actors interact. Thus, the UX approach added to the FEI process aims to verify that the interactions "actors/methods and processes" are of good quality. The target of this paper was to create an instrument allowing to evaluate the experience of co-creators that innovate in the ideation stage of the FEI process. Therefore, the case study concerns the application of creativity methods in the FEI idea generation step. The results show that it is possible to reliably evaluate different elements of the user eXperience experienced during an idea generation activity. Each of these elements belong to a different experience. And each experience that can be reliably evaluated belongs to one of the three dimensions that constitutes the user eXperience. Finally, the results show that it is possible to evaluate the UX of a group of persons who innovates following the FEI process at least for the ideation stage, it is called UXi.

However, this study does not allow studying any casual effect or impact between the quality of $U X i$ and the operational performance of radical innovation projects. But, this study confirms that a group of persons who innovate, live an experience that can be characterise by the $U X i$ instrument for the ideation stage of the FEI.

In perspective, it is essential to apply the $U X i$ evaluation model inside an industrial environment. This in order to evaluate the link between the UXi quality and the operational performance of radical innovation projects that consolidate during the ideation stage. Moreover, the UX-FFE structure proposed in this paper should be used to construct the two others evaluation model of the FEI process respectively allowing to assess $U X S$ and $U X v$.

\section{References}

Ahmed, P.K. (1998) 'Culture and climate for innovation', European Journal of Innovation Management, Vol. 1, No. 1, pp.30-43, http://doi.org/10.1108/14601069810199131. 
Baregheh, A., Rowley, J. and Sambrook, S. (2009) 'Towards a multidisciplinary definition of innovation', Management Decision, Vol. 47, No. 8, pp.1323-1339, https://oi.org/10.1108/ 00251740910984578

Benders, J. and Vermeulen, P. (2002) 'Too many tools? on problem solving in NPD projects', International Journal of Innovation Management, Vol. 6, No. 2, p.163, http://doi.org/10.1142/ S1363919602000574.

Bessant, J. (2018) Toolkit, Retrieved 3 March, 2018, from http://www.innovationportal.info/toolkits/welcome/

Bessant, J. and Tidd, J. (2011) Innovation and Entrepreneurship, Bessant J. and Tidd, J. Eds., 2nd ed., John Wiley and Sons.

Brown, S.L. and Eisenhardt, K.M. (1995) 'Product development: past research, present findings, and future directions', Academy of Management Review, Vol. 20, No. 2, pp.343-378, http://doi.org/10.5465/AMR.1995.9507312922.

Buckler, S.A. (1997) 'The spiritual nature of innovation', Research Technology Management, Vol. 40, No. 2, pp.43-47, http://doi.org/10.1080/08956308.1997.11671116.

Campbell, D.T. and Fiske, D.W. (1959) 'Convergent and discriminant validation by the multitraitmultimethod matrix', Psychological Bulletin, Vol. 56, No. 2, pp.81-105, http://doi.org/ $10.1037 / \mathrm{h} 0046016$

Cooper, R.G. and Kleinschmidt, E. (1987) 'New products: what separates winners from losers?', Journal of Product Innovation Management, Vol. 4, No. 3, pp.168-184.

Cresswell, J.W., Plano-Clark, V.L., Gutmann, M.L. and Hanson, W.E. (2003) 'Advanced mixed methods research designs', Handbook of Mixed Methods in Social and Behavioral Research, 209-240, http://doi.org/10.1017/CBO9781107415324.004.

De Brentani, U. and Reid, S.E. (2012) 'The fuzzy front-end of discontinuous innovation: Insights for research and management', Journal of Product Innovation Management, Vol. 29, No. 1, pp.70-87, http://doi.org/10.1111/j.1540-5885.2011.00879.x.

Dornberger, U. and Suvelza, A. (Eds.) (2012) Managing the Fuzzy Front-End of Innovation, 1st ed., Intelligence 4 innovation, Leipzig.

Frishammar, J., Floren, H. and Wincent, J. (2011) 'Beyond managing uncertainty: insights from studying equivocality in the fuzzy front end of product and process innovation projects', IEEE Transactions on Engineering Management, Vol. 58, No. 3, pp.551-563, http://doi.org/ 10.1109/tem.2010.2095017.

ISO FDIS 9241-210 (2009) Ergonomics of Human System Interaction-Part 210: Human-centered Design for Interactive Systems (formerly known as 13407).

Jewkes, J., Sawers, D. and Stiilerman, R. (1969) The Sources of Invention, 2nd ed., Norton, New York, NY.

Kim, J. and Wilemon, D. (2002) 'Focusing the fuzzy front-end in new product development', $R \& D$ Management, Vol. 32, No. 4, pp.269-279, http://doi.org/10.1111/1467-9310.00259.

Kline, P. (2000) The Handbook of Psychological Testing, 2nd ed., Routledge, London.

Koen, P., Ajamian, G., Burkart, R., Clamen, A., Davidson, J., D’Amore, R., Elkins, C., Herald, K., Incorvia, M., Johnson, A., Karol, R., Seibert, R., Slavejkov, A. and Wagner, K. (2001). 'Providing clarity and a common language to the 'fuzzy front end', Research Technology Management, Vol. 44, No. 2, pp46-55, https://doi.org/Article

Krawczyk, P., Topolewski, M. and Pallot, M. (2017) 'Towards a reliable and valid mixed methods instrument in user eXperience studies', 23rd International Conference on Engineering, Technology and Innovation (ICE-IEEE-TEMS 2017), Funchal, pp.1497-1506.

Law, E.L-C., Roto, V., Hassenzahl, M., Vermeeren, A.P.O.S. and Kort, J. (2009) 'Understanding, scoping and defining user experience', Proceedings of the 27th International Conference on Human Factors in Computing Systems - CHI 09, April 2016, p.719, http://doi.org/ $10.1145 / 1518701.1518813$. 
Lecossier, A. and Pallot, M. (2017) 'UX-FFE model: an experimentation of a new innovation process dedicated to a mature industrial company', 23rd International Conference on Engineering, Technology and Innovation (ICE-IEEE-TEMS 2017), Funchal, pp.557-563.

Lecossier, A., Tcha-Tockey, K. and Richir, S. (2017) 'The user experience measurement: a challenge of the twenty-first century', International Scientific Conference Dedicated to the 175th Anniversary of the D.I. Mendeleyev Institute for Metrology (VNIIM 175), Saint-Petersburg, Book of Abstracts.

Lucas, H. . and Goh, J.M. (2009) 'Journal of strategic information systems disruptive technology: how Kodak missed the digital photography revolution', Journal of Strategic Information Systems, Vol. 18, No. 1, pp.46-55, http://doi.org/10.1016/j.jsis.2009.01.002.

Markham, S.K. (2013) 'The impact of front-end innovation activities on product performance', Journal of Product Innovation Management, Vol. 30, Suppl. 1, pp.77-92, http://doi.org/ 10.1111/jpim.12065.

McLaughlin, P., Bessant, J. and Smart, P. (2008) 'Developing an organisation culture to facilitate radical innovation', International Journal of Technology Management, Vol. 44, Nos. 3/4, p.298, http://doi.org/10.1504/IJTM.2008.021041.

Nicholas, J. (2014) An Investigation into the Practices and Underlying Factors during the Fuzzy Front End of Radical Innovation, Doctoral Thesis, Retrieved from University of Limerick data base, https://ulir.ul.ie/bitstream/handle/10344/4024/Nicholas 2014 investigation.pdf? sequence $=6$

Nunnally, J.C. (1967) Psychometric Theory. Psychometric Theory, McGraw-Hill, New York, NY, USA.

O'Leary-Kelly, S.W. and Vokurka, R.J. (1998) 'The empirical assessment of construct validity', Journal of Operations Management, Vol. 16, No. 4, pp.387-405, http://doi.org/http:// dx.doi.org/10.1016/S0272-6963(98)00020-5.

Pallot, M. and Pawar, K. (2012) 'A holistic model of user experience for living lab experiential design', 2012 18th International ICE Conference on Engineering, Technology and Innovation, Munich, pp.1-15, http://doi.org/10.1109/ICE.2012.6297648

Pihlajamaa, M. (2017) 'Going the extra mile: Managing individual motivation in radical innovation development', Journal of Engineering and Technology Management - JET-M, Vol. 43, pp.48-66, http://doi.org/10.1016/j.jengtecman.2017.01.003.

Porter, M.E. (1985) Competitive Advantage - Creating and Sustaining Superior Performance, The Free Press, New York, NY, USA.

Prather, C.W. (2000) 'Keeping innovation alive after the consultants leave', Research-Technology Management, Vol. 43, No. 5, p.17.

Rajapathirana, R.P.J. and Hui, Y. (2017) 'Relationship between innovation capability, innovation type, and firm performance', Journal of Innovation \& Knowledge, http://dx.doi.org/10.1016/j.jik.2017.06.002

Reid, S.E. and De Brentani, U. (2004) 'The fuzzy front end of new product development for discontinuous innovations: a theoretical model', Journal of Product Innovation Management, Vol. 21, No. 3, pp.170-184, http://doi.org/10.1111/j.0737-6782.2004.00068.x.

Rolstadås, A., Henriksen, B. and O'Sullivan, D. (2012) 'The innovation process', Manufacturing Outsourcing: A Knowledge Perspective, Springer London, pp.129-144, http://doi.org/ 10.1007/978-1-4471-2954-7 15.

Scapin, D.L., Senach, B., Trousse, B. and Pallot, M. (2012) 'User experience: buzzword or new paradigm?', ACHI 2012 - 5th International Conference on Advances in Computer-Human Interactions, January, pp.336-341, Retrieved from http://www.scopus.com/inward/record. url? eid=2-s2.0-84883218765\&partnerID=40\&md5=744ea909df799253f848d5c5953ff24e

Tatikonda, M.V. and Rosenthal, S.R. (2000) 'Technology novelty, project complexity, and product development project execution success: a deeper look at task uncertainty in product innovation', HPAC Heating, Piping, Air Conditioning, Vol. 72, No. 2, pp.74-87, http://doi.org/10.1109/17.820727. 
Verworn, B., Herstatt, C. and Nagahira, A. (2008) The Fuzzy Front End of Japanese New Product Development Projects: Impact on Success and Differences between Incremental and Radical projects, October, pp.1-19, http://doi.org/10.1111/j.1467-9310.2007.00492.x.

Zhang, Q. and Doll, W.J. (2001) 'The fuzzy front end and success of new product development: a causal model', European Journal of Innovation Management, Vol. 4, No. 2, pp.95-112, http://doi.org/10.1108/14601060110390602.

\section{Appendices}

Appendix A Overall UX-FFE Construct including 4 levels, namely: dimensions, experience, elements and properties

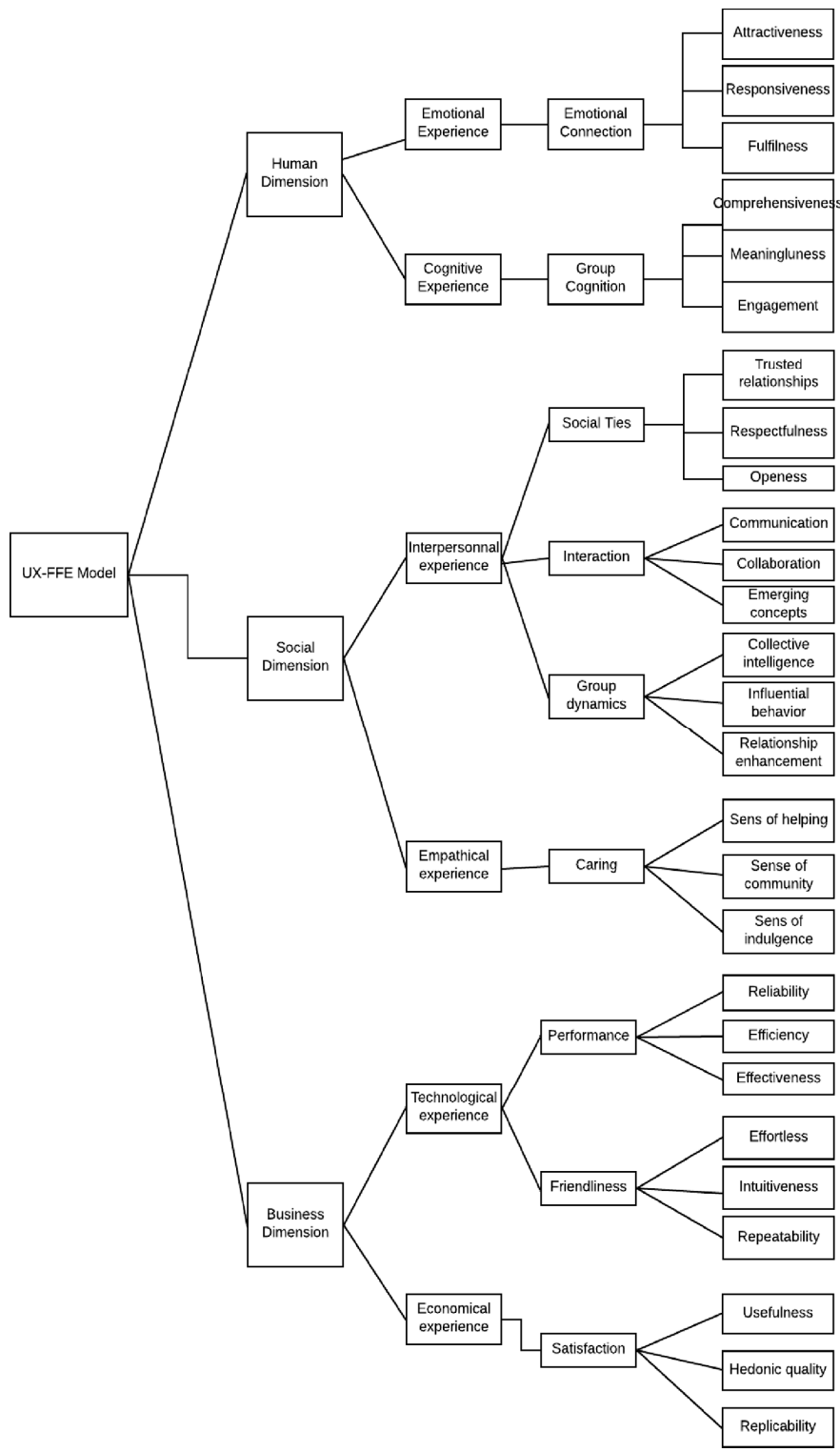


Appendix B Pearson correlations of items (frames show lower level and upper level experiences) (see online version for colours)

\begin{tabular}{|c|c|}
\hline & $1-1-1=1-1=0$ \\
\hline Hedonic quality & 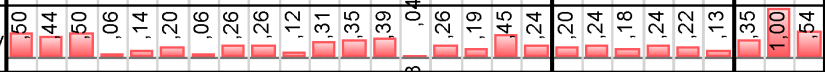 \\
\hline & 电 \\
\hline Repez & 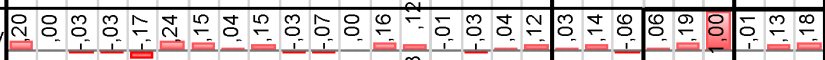 \\
\hline Intuitiveness & F \\
\hline Effortless & 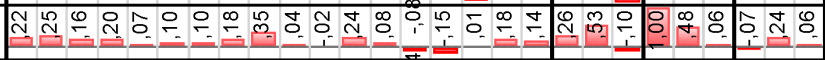 \\
\hline Effectiveness & 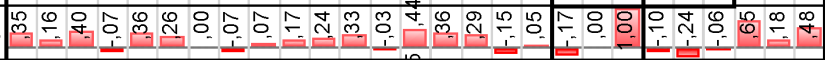 \\
\hline Efficiency & N్ల్m \\
\hline Reliability & 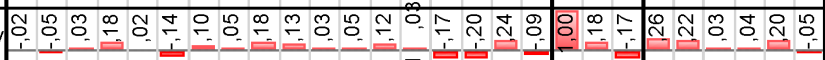 \\
\hline & 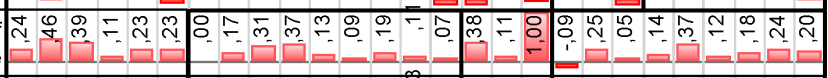 \\
\hline & 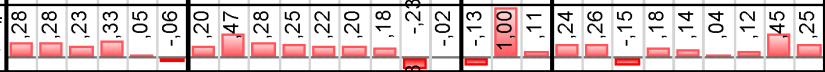 \\
\hline ping & 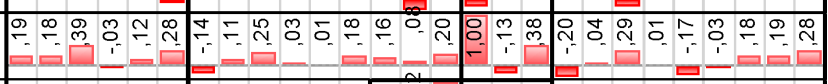 \\
\hline & 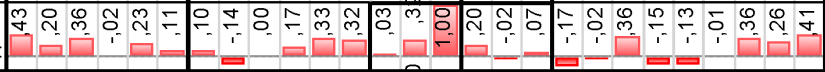 \\
\hline & 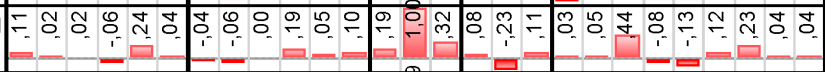 \\
\hline & 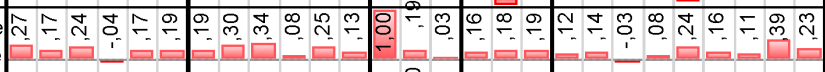 \\
\hline & 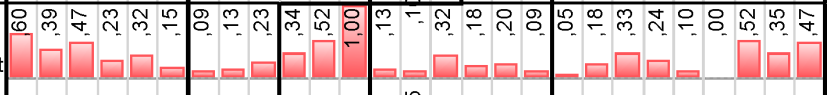 \\
\hline & 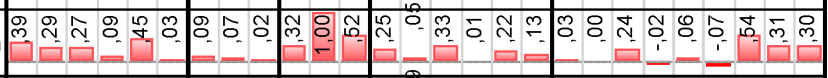 \\
\hline Commun & 尾 \\
\hline & 욜 \\
\hline Respectfulness & 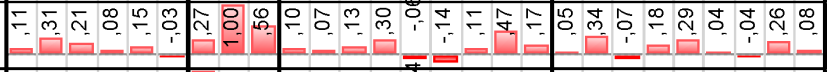 \\
\hline & 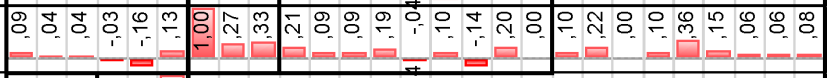 \\
\hline & 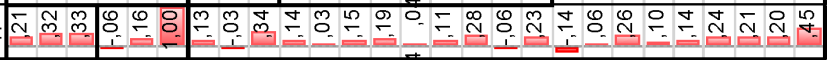 \\
\hline uness & 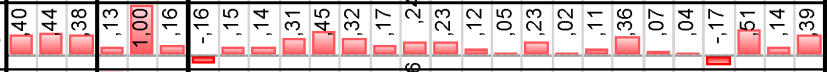 \\
\hline $\begin{array}{r}\text { siven } \\
\text { ess }\end{array}$ & 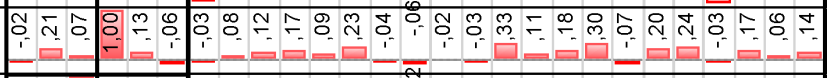 \\
\hline & 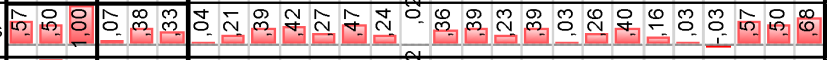 \\
\hline ess & 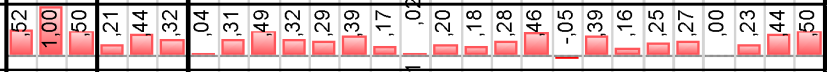 \\
\hline & : \\
\hline & 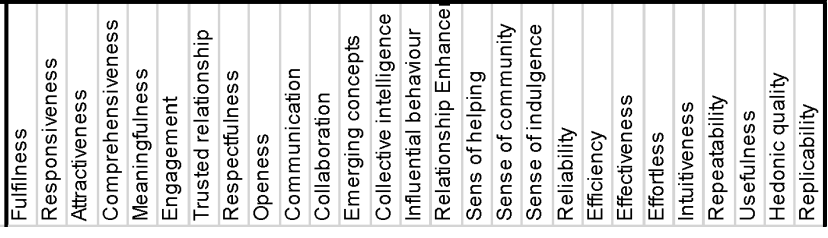 \\
\hline
\end{tabular}

